ARTICLE HISTORY: Received: October 20, 2021 Accepted: December 12, 2021 Published: December 19, 2021

\title{
EFFECT OF DIALOGIC TEACHING ON ENGLISH SPEAKING SKILLS
}

\author{
Toleugalieva Danagul \\ Makhambet Utemisov West Kazakhstan University, \\ Uralsk, Kazakhstan
}

\begin{abstract}
This paper aims to investigate the influence of dialogic teaching on the development of the learners' speaking skills. It is questioning why Kazakh students are unable to express themselves efficiently and comfortably. This seems crucial and imperative for students and it shouldn't shape any obstacle for future development. Accordingly, this paper poses a significant issue that every learner of English needs to ponder. To collect data for the study, three tools has been used; a questionnaire, an interview and an observation. The questionnaire was distributed throughout the students who had been selected from different universities. The collected data is analyzed quantitatively and qualitatively. Data analysis has shown that dialogic teaching enables students to develop the skills of argumentation, questioning and debate which contribute to the development of their speaking skills. Generally, the findings indicate that authentic dialogic teaching components are effective if students are given enough time to practice its skills.
\end{abstract}

Key words: dialogic teaching, English language learners, speaking skills.

\section{Introduction:}

Students encounter difficulties to express themselves comfortably and efficiently either when dealing with academic topics or every day topics. The researchers think that, dialogic teaching method is one of the effective strategies moreover they considered it to be the educative potential of teacher - student interaction that enables students to play active part in shaping the topics of classroom discourse.

Dialogic teaching which is collective, reciprocal, cumulative, stresses the potential of collaborative, group work and peer assistance to promote mutually responsive learning in the zone of proximal development.

Objectives of the paper:

The present paper is aiming to achieve the following objectives:

1. To investigate the role of dialogic teaching in developing learners' speaking skills.

2. To explain the role of dialogic teaching in engaging learners through the medium of speaking.

\section{Materials and methods:}

Two methods were used: Quantitative analysis was used for analyzing the data collected through questionnaire and check list. The analysis was done by using the statistical package for social science program and the results were represented in the form of frequencies and percentage tables and figures.

Qualitative analysis was used for analyzing interviews, where interviews, and documents are the typical sources of qualitative data which can be captured on audio recording or video, cameras, charts and most commonly textual transcriptions. These texts, documents and recordings are analysed for their meaningful content and they are interpreted rather than counted or measured.

Grounded in the principles of collectivistic, reciprocity, support, cumulating and purposefulness, dialogic teaching draws on recent psychological and neuroscientific research on children's development and cognition as well as on a long tradition of observational and process-product research on teaching. [1, p.10]. The approach links with the work of Bakhtin, (Bakhtin, M. (1986), The impact of Dialogic Teaching on English Language. Barnes, Mercer, Bruner, J. S. (1978). and with new developments in cultural psychology and activity theory. Dialogic teaching has been intensively trailed in London, Yorkshire and other parts of Britain [6, p. 22].

Practicing dialogic teaching according to Alexander is based on the six pedagogical values which start with the purposes of education, the nature of knowledge and the relationship between teacher and learner:

1)Teaching as transmission sees education primarily as a process of instructing children to absorb, replicate and apply basic information and skills.

2)Teaching as initiation sees education as the means of providing access to, and passing on from one generation to the next, the culture's stock of high-status knowledge, for example in literature, the arts, humanities and the sciences.

3)Teaching as negotiation reflects the Deweyan idea that teachers and students jointly create knowledge and understanding rather than relate to one another as authoritative source of knowledge and its passive recipient.

4)Teaching as facilitation guides the teacher by principles which are developmental (and, more specifically, Piagetian) rather than cultural or epistemological. The teacher respects and nurtures individual differences, and waits until children are ready to move on instead of pressing them to do so.

5)Teaching as acceleration, in contrast, implements the Vygotskian principle thateducation is planned and guided acculturation rather than facilitated 'natural' development, and indeed that the teacher seeks to outpace development ratheк than follow it. 
6)Teaching as technique, finally, is relatively neutral in its stance on society, knowledge and the child. Here the important issue is the efficiency of teaching regardless of the context of values, and to that end imperatives like structure, economic use of time and space, carefully graduated tasks, regular assessment and clear feedback are more pressing than ideas such as democracy, autonomy, development or the disciplines [2, p. 6].

1. Dialogic teaching approach

- Dialogic teaching is an approach and a professional outlook rather than a specific method. It requires teachers to rethink not just the techniques they use but also the classroom relationships. They foster, the balance of power between teachers teaching performance and the way they conceive knowledge. [9, p. 31].

- Dialogic teaching, like all good teaching, is grounded in evidence and principles.

- And like all good teaching it draws on a broad repertoire of strategies and techniques.

- The teacher draws on this repertoire in response to different educational purposes and contexts, the needs of different pupils, and the diverse character of what is to be taught and learned. [10, p.85]

Dialogic teaching has five principles that has been identified by Alexander, R:

- The talk of everyday life is identified by sociolinguists as any kind of talk which empowers and support everyday human interactions. The kind of talk that educational institutions perform to help learners to develop, explore and use each of these: transactional talk, expository talk, interrogatory talk, exploratory talk, expressive talk, and evaluative talk [3, p. 37].

- Learning talk. In dialogic teaching learners do not just provide brief factual answers to test or recall questions, or merely spot the answer which they think the teacher wants to hear. Instead they learn to: narrate, explain, analyze, speculate, imagine, explore, evaluate, discuss, argue, justify and they ask questions of their own.

- Teaching talk. In dialogic classrooms teachers may use familiar kinds of teaching talk such as rote, recitation, instruction. But in dialogic classrooms teachers do not limit themselves to these. They also use: discussion, scaffold dialogue.

- Classroom organization [4, p. 91].

What is dialogic teaching? The term "dialogic teaching" is particularly associated with Alexander's focus on talk between teachers and students in the classroom. Alexander's point in using this Bakhtinian definition of dialogue is that it is only by engaging in live dialogue, either with each other, directly with the teacher, or vicariously by listening to others in dialogue, that students learn to think. [3, p.46] This understanding of dialogue as a form of open ended shared inquiry links Alexander's 'dialogic teaching' to Nystrand's “dialogic instruction' (1997), Matusov's 'dialogic pedagogy' (2009), Wells' 'Dialogic inquiry' (1999), and Wegerif's 'Dialogic education'. In other words, the aim of education is not only that the students will learn something that the teacher already knows but also that the students will learn how to ask open questions a nd how to learn new things for themselves through engaging in dialogic inquiry. [12, p. 97].

Dialogic teaching components. Studies of classroom communication have identified five components of dialogic teaching and they have been referred to as patterns of interaction these are; exploratory talk, argumentation, effective questioning, debate and dialogue [13, p. 9].

These components are believed to promote high level of understanding and intellectual development through their capacity to invo lve teachers and learners in joint acts of meaning - making and knowledge construction.

The word dialogue comes from two Greek roots, dia and logos, suggesting "meaning following through". In common sense, 'Dialogue' is defined as a process of conversation between two or more persons for exchanging.

- Dialogue seems to be emerging as a cornerstone for "organizational learning".

- Dialogue appears to be a powerful way of harnessing the inherent-organizing collective intelligence of groups of people and of both broadening and deepening the collective inquiry process.

- Dialogue shows possibilities for being an important breakthrough in the way people might govern themselves, whether in public or private domains.

- Dialogue shows promise as an innovative alternative approach to producing coordinated action among collective.

The relationship between dialogue and pedagogy. Smith and Higgins (2006) suggest that the focus of attention should be placed, not on the questions that teachers ask, but more on the way in which they react to learners' responses; in this they share some commonality with Alexander' notion of an 'emerging pedagogy' of talk as means of helping to shape and develop learners' engagement with learning and understanding [5, p. 61].

Promotion of pedagogic dialogue

Moore believes that the discourse of the 'charismatic' teacher is a powerful myth founded on Burner's notion of 'folk pedagogy' [7, p. 95]. He suggests that 'charisma', the characteristic regularly cited by students as paramount in a good teacher, might be better conceptualized as 'communicative'.

The power of dialogic approaches to learning and teaching can extend beyond whole class teaching. Indeed, it may argued that productive use of cognitively stimulating dialogue could be explored most fruitfully in small-group learning. This, however, does not appear to be widely recognized by teachers as practice that promotes thinking and understanding. As Baines et al. (2003, p.31) point out, "creating effective group-working tasks and conditions is harder and more time consuming than a traditional independent and didactic learning approach". It may also be the result of a lack of understanding of ways to scaffold dialogue, and of what their talk role might be in promoting this [8, p. 351]. 


\section{Results and Discussions:}

This part consists of two sections. The first section is concerned with the analysis and discussion of the data obtained from students' questionnaire. The second section deals with the English language lecturers' responses to the interview which was designed to get their viewpoints on the influence of dialogic teaching on the development of the learners' speaking skills and thinking.

Dialogic teaching enhances the learners' skills of speaking. According to the researcher's view point, this high percentage indicates the effectiveness of dialogic teaching enable the learners to value the difference between dialogic teaching and didactic teaching. In addition, it may refer to the fact that this type of teaching maximizes students' talking time which in turn enhances their speaking skills. Dialogic teaching develops the learner's thinking. This proves that dialogic teaching can give students the opportunity to extend their talk and their thinking. The development of the learners' of reasoning can be achieved through mastering argumentation skills. Using the technique of dialogue in teaching provides the learners with opportunity to listen to each other. Dialogic teaching develops the learner's debating skills.

Teachers stated that dialogic teaching improves learners' influence and speech mechanisms through teaching students to take turns and have positive roles. Also it gives students a chance to think critically, develop influence, and empower them to express their views freely and confidently. Only one respondent did not think that dialogic teaching is effective in developing dialogue, debate, argumentation and questioning skills of students because the teacher controls the class through this way, i.e. the teacher becomes the center of the class which restricts the ability of students in dialogue, debate, argumentation and questioning skills. When discussing the effectiveness of the above mentioned skills in developing learners' speaking and thinking skills, almost all respondents stated that all the above skills, with more concentration on debate and argumentation skills which provide learners with chances to exchange and share their ideas with each others, so this will help them to expand their ideas and thoughts which will improve their thinking and speaking skills. One of the interviewees believe that only dialogue and questioning skills suit student's knowledge and experience at this stage. Students at this level are unable to use debate and argumentation skills in class. Another interviewee said that dialogue is the most effective skill because all students can participate through using dialogue. He also stated that questioning technique is important in refreshing learner's ideas and thoughts. Most of the interviewed teachers stated that there are many challenges facing dialogic teaching in Kazakh universities such as the lack of enough time, motivation, students' language proficiency levels and the influence needed to develop these skills. The major challenge is how to offer adequate training for teachers on modern techniques of dialogic teaching. [11, p.58]

Analyzing the interviews, students' responses to the questionnaire and the performance of the participants in the classroom debate activity has come out with the following results:

1. Dialogic teaching provides an opportunity for students to be actively engaged.

2. Dialogic teaching enables students to develop the skills of argumentation, questioning and debate which contribute to the development of their thinking and speaking skills.

3. Dialogic teaching uses techniques such as dialogue, questioning, argumentation and debates to allow the teacher and his/her students to address the learning task together.

4. In dialogic teaching, learners are active participants in the teaching - learning processes.

5. Asking questions frequently during class discussion is positively related to good achievement in communication skills.

6. Debates as an active instructional strategy enhances learning particularly in the areas of developing thinking skills and oral communication.

7. Dialogic teaching develops learners' thinking and speaking skills if it is applied on its scientific basis.

8. Dialogic teaching provides learners the opportunity to practice effectively speaking skills.

9. Dialogic teaching components are effective if students are given enough time to practice these skills.

10. These skills can be effective if they are practiced in authentic communicative situations.

11. The effectiveness of dialogic teaching depends on the teacher who is supposed to be of high proficiency and aware of these techniques.

\section{Conclusion:}

The components of dialogic teaching skills which had been tested throughout the research, they explained that they are effective and interactive in learners' speaking and thinking. The most essential results are explored by some interviewees who stated that dialogue skills and questioning skills are the most effective and applicable in the classroom than the other components of dialogic teaching. Moreover, debate includes questioning, argumentation and dialogue between the participating teams which proved that it is effective and inclusive component. Among some of the experts who were interviewed stated that argumentation is effective in developing learners' thinking skills if they are introduced to basic vocabulary and technique of claims and refutations. Dialogic teaching is faced by a number of challenges such as the time available for both students and teachers, motivation to speak the language, proficiency level and fluency needed to develop such skills. In order to make dialogic teaching the interactive method to develop learners' speaking and thinking, the raised challenges should be addressed. This study seeks to identify the effect of dialogic teaching methods on university students' critical thinking. It is commonly believed that teachers rely on language that allows only 
minor flexibility when exchanging views with their students. Too frequently they either pose questions that target predefined answers or simply lecture through lessons. This paper displays the introduction of the Communicative Approach drawing on dialogic teaching which means using talk most effectively for carrying out teaching and learning. Dialogic teaching involves ongoing talk between teacher and students, not just teacher-presentation. Here we show the most effective components of dialogic teaching skills that stimulate teacher-student interaction. However, dialogic teaching is faced with some challenges which exemplified in lack of adequate fluency and students' motivation.

\section{REFERENCES:}

[1] Alexander, R. (2005). Teaching through dialogue. London: Barking and Dagenham. [in English].

[2] Alexander, R. J. (2008). Towards dialogic teaching. York: Dialogos. [in English].

[3] Alexander, R. (2004). Towards Dialogic Teaching: Rethinking classroom talk. Cambridge: Dialogos. [in English].

[4] Cazden, C. B. (2001). Classroom Discourse: The Language of Teaching and Learning. Porthmouth, NH: Heinemann Fisher, A. (2011). [in English].

[5] Fisher R. (2006). Dialogic teaching: Developing thinking and meta-cognition throug philosophical discussion. Early Childhood Development and care. 177(6-7), 615-631. [in English]

[6] Mercer, N., Wegerif, R. \& Dawes, L. (1999). Exploring Talk in School: inspired by the work of Douglas Barnes. London: Sage. [in English].

[7] Moore, A. (2004). The good teacher: Dominant discourse in teaching and teacher education. London: Routledge. reasoning in the classroom, British Educational Research Journal, 25, 1, pp. 95. [in English].

[8] Wegerif, R. (2008). Dialogic Education: What is it and why do we need it? British Educational research Journal, 34(3), 347-361. [in English].

[9] Wegerif, R. Dialogic or dialectic? The significance of ontologic assumptions in research on educational dialogic. British Educational Research Journal, Volume 8. Number 4. December 2017[in English].

[10] Wolfe, S. (2006). The impact of Dialogic Teaching on English Language. [in English].

[11] Wood, D., Bruner, J. S., \& Ross, G. (1976). The Role of Tutoring in Problem Solving. [in English].

[12] Wegerif, R. (2008). Teaching and learning through dialogue. England. University of Cambridge. The role of tutoring in problem solving. Journal of Child Psychology and Psychiatry, 17, 89-100. [in English].

[13] Wegerif, R. Dialogic or Dialectic? The significance of ontological assumptions in research on Educational Dialogue. British Educational Research Journal, DOI: 10.1080/1411920701532228. (5th highest cited article, 2013) [in English]. 